\title{
A PESQUISA DE ALEKSEI N. LEONTIEV SOBRE A MEMÓRIA E SEU SIGNIFICADO COMO VANGUARDA NA CIÊNCIA SOVIÉTICA DO FUTURO
}

\author{
ALEKSEI N LEONTIEV'S RESEARCH ON MEMORY AND \\ ITS MEANING AS THE SOVIET AVANT-GARDE \\ SCIENCE OF THE FUTURE
}

Anton Yasnitsky ${ }^{1, *}$

RESUMO: Este artigo apresenta um reconhecido psicólogo soviético do Círculo VigotskiLuria, Aleksei N. Leontiev, traz uma visão geral de suas contribuições para a pesquisa em psicologia e explora a vertente Vigotski-Leontiev-Zinchenko dos estudos psicológicos sobre a memória humana e a recordação. O quadro geral da "ciência do super-homem" vigotskiana como componente da singular ciência soviética de vanguarda também é abordado neste artigo.

Palavras-chave: Lev Vigotski. Ivan Pavlov. Aleksei N. Leontiev. Memória. Recordação.

ABSTRACT: This paper presents a notable Soviet psychologist of the Vygotsky-Luria Circle, Aleksei N. Leontiev, overviews his contribution to psychological research, and explores the Vygotsky-Leontiev-Zinchenko strand in psychological studies of human memory and remembering. The general framework of Vygotskian "Superman science" as a component of the unique Soviet avant-garde science is also covered in this paper.

Keywords: Lev Vygotsky. Ivan Pavlov. Aleksei N. Leontiev. Memory. Remembering.

1.Pesquisador autônomo - Toronto, Canada.

*Autor correspondente: anton.yasnitsky@gmail.com

$\mathrm{O}$ artigo aqui apresentado pelo autor defende ponto de vista que pode ser mais bem-compreendido a partir do corpo da sua obra. Nesse sentido, chamamos atenção para alguns dos seus textos, que podem ser consultados em http://individual.utoronto.ca/yasnitsky/

Dossiê organizado por: Gisele Toassa e Ana Luiza Bustamante Smolka 


\section{Aleksei N. Leontiev: Três Razões para Lembrar este Nome}

Aleksei N. Leontiev (1903-1979) foi um psicólogo soviético cujos legado e vida estão intimamente associados aos nomes e legados acadêmicos de intelectuais soviéticos proeminentes, como o neuropsicólogo Alexander Luria (1902-1977) e o psicólogo do desenvolvimento Lev Vigotski (1896-1934). Esse último é bem-conhecido como o terceiro membro da "troika" (os três, ou o trio, em russo) de intelectuais russos na lista dos "100 mais eminentes psicólogos do século XX” (ocupando a 83a posição e seguindo seus contemporâneos Ivan Pavlov [1849-1936], em 24 lugar, e Alexander Luria, que ocupa o 69 lugar na lista), conforme estudo realizado por acadêmicos norte-americanos no início do século XXI (HAGGBLOOM et al., 2002). Graças a essa associação com os psicólogos russos mais eminentes (sendo essa a primeira razão para lembrar seu nome), Leontiev é conhecido hoje - mas esse certamente não isso é o único motivo.

A segunda razão da fama histórica de Leontiev, sobretudo em seu país natal, é sua proeminência na história da psicologia russa na era soviética, como grande força administrativa e organizacional, sendo o fundador e o primeiro reitor de um dos dois institutos nacionais de psicologia, ambos oficialmente autorizados em dezembro de 1965 e inaugurados na União Soviética em 1966. Em virtude de um conjunto de fatores como encanto pessoal, carisma, fluência em francês, que sugeria o jeito aristocrático tão admirado na época em certos círculos da intelligentsia russa, aliados a suas apresentações orais e escritas sabidamente obscuras, que criavam uma imagem de enigma e aludiam à posse de um conhecimento misterioso e supremo de um douto -, Leontiev se tornou uma figura cultuada por seus inúmeros admiradores e seguidores no Lomonosov Moscow State University (MSU), que viria a ser o reduto do clã leonteviano até o fim da sua vida. Logo após sua morte, em 1979, o reinado de Leontiev no MSU passou por reviravoltas e foi tomado pelo clã rival de psicólogos russos da segunda faculdade de psicologia mais poderosa, a Universidade Estadual de Leningrado (renomeada São Petersburgo), também inaugurada em 1966. O arquiteto desse golpe administrativo foi Boris Lomov (1927-1989) - personagem com conexões mais influentes do que as de Leontiev nas altas esferas do regime do Partido Comunista na União Soviética -, em conjunto com grande número de colaboradores e membros de sua rede de relações clientelistas. Essa tomada de poder desencadeou uma disputa pelo domínio em escala local e, depois de certo tempo, em $2000^{1}$, os membros remanescentes do clã leontieviano reconquistaram o poder na Faculdade de Psicologia da Universidade Estadual de Moscou. Por isso, essa universidade segue sendo, talvez, o único reduto dos antigos alunos de Leontiev e um local privilegiado de culto a esse estudioso no século XXI, ainda que os encantos, tanto do culto quanto do legado da sua principal figura, tenham diminuído consideravelmente neste milênio.

Adicionalmente, existe uma terceira razão para que a imagem de Aleksei N. Leontiev não tenha desvanecido em absoluto esquecimento póstumo, como ocorreu com diversos e grandes intelectuais anteriores ou posteriores a ele: suas teorização e especulação marxistas - ou quase marxistas, como diriam alguns - no campo da psicologia e em áreas afins de conhecimento. Esse aspecto de seu legado intelectual nos direciona à pré-história do que atualmente denomina-se, na União Soviética, "psicologia histórico-cultural" e "teoria da atividade", conforme desenvolvidas pelos membros do assim chamado Círculo Vigotski-Luria (YASNITSKY, $2016 b)^{2}$.

Historicamente, três nomes são frequentemente associados ao Círculo: Vigotski, Luria e Leontiev. É comum que sejam descritos como a "troika" criadora, com exclusividade, da "teoria histórico-cultural" na União Soviética antes da Segunda Guerra Mundial. Tal retrato é definitivamente equivocado e não coincide com as evidências que temos agora. Primeiramente, o rótulo "histórico-cultural" surgiu em meio às discussões críticas das pesquisas de Vigotski e Luria no começo da década de 1930 e foi, em seguida, assimilado pelos seguidores de Vigotski e pela comunidade acadêmica mais ampla, após o falecimento desse pesquisador 
(KEILER, 2019). Em segundo lugar, tal teoria nunca chegou a ser criada por Vigotski, tampouco por Luria ou qualquer dos seus colaboradores: foi produzido apenas um apanhado de rascunhos teóricos - muitas vezes inconsistentes ou contraditórios - do sistema psicológico de pensamento, os quais poderiam, em conjunto, justificar a reivindicação de várias teorias na psicologia, mas, definitivamente, não uma única teoria bemacabada. Em terceiro lugar, os três protagonistas-chave da narrativa da "troika" se mantiveram relativamente unidos por curto período, aproximadamente de 1926 a 1930, até ocorrer um gradativo distanciamento, por vários motivos, em 1930. Por fim, os papéis dos três estudiosos dentro do Círculo eram muito distintos.

Luria foi parceiro e colaborador de longa data de Vigotski: a dupla teve larga trajetória de interrelações e trabalhou produtivamente numa série de projetos de pesquisa e escrita. Além disso, a despeito das declarações de Luria em múltiplas ocasiões, ele não foi apenas o humilde seguidor e aluno de Vigotski, mas também influenciou de maneira instrumental a essência de seus pensamento e teorização (LAMDAN, 2019). Em contrapartida, Leontiev sempre desempenhou papel subalterno no trabalho da dupla de pesquisadores, embora tenha contribuído significativamente para o trabalho do Círculo no período reducionista e mecanicista da assim-chamada "psicologia instrumental". Apesar disso, pode-se dizer que Leontiev foi o melhor aluno de Vigotski de todos os tempos.

O projeto singular e idiossincrático de Vigotski nas ciências humanas, como inúmeras vezes mostrado em suas apresentações orais, escritos particulares e trabalhos publicados no decorrer da última década de sua vida, foi a busca por uma "nova psicologia", que ele também formulou como "ciência de Superhomem" ou "psicologia da excelência", a qual (a) pretende atingir as alturas (em oposição às "profundidades" freudianas ou ao "nível de superfície" dos comportamentos cotidianos que interessam aos behavioristas de várias linhas) do (b) ser humano supremo em potencial (em oposição ao tipo humano mediano que de fato existe). Tem sido, em grande parte, ignorado esse aspecto central da proposta singular de Vigotski como instância perfeita dos experimentos revolucionários ousados e radicais nas ciências humanas - como a busca científica pela extensão da vida e até mesmo pela imortalidade (KREMENTSOV, 2013) - e na "ciência de vanguarda" nitidamente soviética ${ }^{3}$ da pesquisa psicológica. Tal aspecto foi trazido à luz bem recentemente (YASNITSKY, 2019).

Existe, também, outra importante proposta de Lev Vigotski no plano metodológico e conceitual. Trata-se da demanda por um "materialismo psicológico", que ele defendeu, em analogia ao "materialismo histórico" de Karl Marx e Friedrich Engels, como quadro metodológico e conceitual que residiria entre a filosofia propriamente dita e a pesquisa histórica e sociológica concreta. Semelhantemente, a proposta de Vigotski por um "materialismo psicológico" refletia a necessidade que se percebia de uma base de conhecimento em nível intermediário entre a filosofia marxista e a pesquisa psicológica concreta - tanto teórica quanto empírica - no contexto do mundo real e nos contextos de aplicação na União Soviética das décadas de 1920 e 1930.

Vigotski propôs que fosse escrito um livro sobre o "materialismo psicológico", que ele, porém, nunca chegou a escrever. De fato, em retrospecto, nenhuma de suas duas principais propostas - quais sejam, uma "nova psicologia", verdadeiramente científica, do Super-homem, e o "materialismo psicológico" - foi concretizado durante sua vida. No entanto, a última frase da conclusão do obituário que Leontiev publicou em 1934 afirma de modo inequívoco que: "Aquilo que L. S. Vigotski fez para a ciência não morrerá, pois constitui o primeiro estágio do movimento em direção à psicologia marxista verdadeiramente científica" (LEONTIEV, 1934). Assim, Leontiev pode realmente ser considerado o melhor aluno de Vigotski, por ter sido o único acadêmico da época a se dedicar ao desenvolvimento da teoria psicológica marxista geral e abrangente de Vigotski. Não obstante, os resultados materiais desse esforço - manuscritos e publicações só emergiram depois da morte de Vigotski. 


\section{Um Breve Panorama Geral das Publicações de Aleksei N. Leontiev}

Em vida, Leontiev produziu inúmeras publicações: a lista mais atualizada de seus trabalhos acadêmicos publicados contabiliza 282 itens, além de outras publicações não acadêmicas, artigos em jornais, periódicos, entrevistas, artigos populares etc. (a bibliografia está disponível on-line em: http://www.anleontiev. smysl.ru/sp_publ.htm). Pelo que consta, Leontiev não produziu muitos livros.

Tabela 1. Monografias e principais livros de Aleksei N. Leontiev.

\begin{tabular}{|c|c|c|c|c|c|}
\hline $\begin{array}{l}\text { Título do livro } \\
\text { em inglês }\end{array}$ & $\begin{array}{l}\text { Título do livro } \\
\text { em russo }\end{array}$ & Editora & $\begin{array}{c}\text { Ano da } \\
\text { primeira } \\
\text { publicação }\end{array}$ & Páginas & Gênero \\
\hline $\begin{array}{c}\text { Memory } \\
\text { Development }\end{array}$ & $\begin{array}{l}\text { Razvitie pamiati. } \\
\text { Eksperimental'noe } \\
\text { razvitie vysshikh } \\
\text { psikhologicheskikh } \\
\text { funktsii }\end{array}$ & Uchpedgiz & 1931 & 280 & Monografia \\
\hline $\begin{array}{c}\text { Rehabilitation } \\
\text { of Hand Function }{ }^{4}\end{array}$ & $\begin{array}{l}\text { Vosstanovlenie } \\
\text { dvizheniia. Issledovanie } \\
\text { vosstanovleniia funktsii } \\
\text { ruki posle raneniia }\end{array}$ & Sovetskaia nauka & 1945 & 231 & $\begin{array}{l}\text { Monografia } \\
\text { (em colabora- } \\
\text { ção com A. V. } \\
\text { Zaporozhets) }\end{array}$ \\
\hline $\begin{array}{l}\text { Outline of the } \\
\text { Psyche } \\
\text { Development }\end{array}$ & $\begin{array}{c}\text { Ocherk } \\
\text { razvitiia psikhiki }\end{array}$ & $\begin{array}{l}\text { Voennyi pedagogicheskii } \\
\text { institut Sovetskoi Armii }\end{array}$ & 1947 & 120 & $\begin{array}{c}\text { Monografia/ } \\
\text { Brochura }\end{array}$ \\
\hline $\begin{array}{l}\text { The Problems } \\
\text { of Psyche } \\
\text { Development }\end{array}$ & $\begin{array}{c}\text { Problemy } \\
\text { razvitiia psikhiki }\end{array}$ & $\begin{array}{c}\text { APN RSFSR (1st ed.); } \\
\text { Mysl' (2nd ed.); } \\
\text { Izdatel'stvo Moskovskogo } \\
\text { Universiteta } \\
\text { (3rd \& 4th ed.) } \\
\end{array}$ & 1959 & 496 & $\begin{array}{l}\text { Coletânea de } \\
\text { artigos }\end{array}$ \\
\hline $\begin{array}{c}\text { Activity. } \\
\text { Consciousness. } \\
\text { Personality }\end{array}$ & $\begin{array}{l}\text { Deiatel'nost'. } \\
\text { Soznanie. } \\
\text { Lichnost' }\end{array}$ & Politizdat & 1975 & 304 & $\begin{array}{l}\text { Coletânea de } \\
\text { artigos }\end{array}$ \\
\hline
\end{tabular}

Curiosamente, apenas três itens da lista podem ser considerados monografias principais do autor, ou seja, livros que Leontiev escreveu na íntegra (ou relativamente na íntegra), independentemente, como projetos especializados de finalidade única. Mesmo assim, um dos três - a Reabilitação da Função Manual, de 1945 (item 29 na lista) - teve como coautor um de seus ex-alunos, Aleksandr Zaporozhets (1905-1981). Outro livro é uma brochura estendida de 120 páginas, uma versão curta da tese de doutorado de Leontiev, escrita sob orientação do herdeiro administrativo e intelectual de Ivan Pavlov, o fisiologista Leon Orbeli (1882-1958). A tese foi defendida em Leningrado, no ano de 1940 (o manuscrito foi perdido durante a Segunda Guerra Mundial). O restante é composto de artigos acadêmicos, verbetes de enciclopédias, folhetos/ apostilas, coletâneas e compilações de textos já publicados pelo autor, como as duas obras bastante conhecidas - Ensaio sobre o Desenvolvimento do Psiquismo [Problemy razvitiia psikhiki] (cuja primeira edição data de 1959) e Atividade. Consciência. Personalidade [Deiatel'nost'. Soznanie. Lichnost'] (cuja primeira edição data de 1975). Trata-se de obra publicada em duas edições apenas quatro anos antes da morte do autor, muitas vezes situada e discutida como a principal obra teórica de Leontiev, a qual resume todo o legado intelectual amealhado na etapa final de sua vida. Contudo, é preciso ter em 
mente que Atividade. Consciência. Personalidade (1975, 2. ed. 1977) não representava um livro inteiramente novo, mas uma coletânea de artigos acadêmicos publicados em diferentes ocasiões, de 1947 a 1974.

Tabela 2. Atividade. Consciência. Personalidade de A N Leontiev (1975):

Composição do livro e cronologia de seus capítulos na primeira publicação.

\begin{tabular}{|c|c|c|c|c|}
\hline \multirow{2}{*}{$\begin{array}{l}\text { Número do } \\
\text { capítulo }\end{array}$} & \multirow{2}{*}{ Título do capítulo } & \multirow{2}{*}{ Título original } & \multicolumn{2}{|l|}{ Primeira publicação } \\
\hline & & & Fonte & Ano \\
\hline I & $\begin{array}{c}\text { Marksizm i } \\
\text { psikhologicheskaia nauka }\end{array}$ & $\begin{array}{c}\text { Karl Marks i } \\
\text { psikhologicheskaia nauka }\end{array}$ & $\begin{array}{l}\text { Voprosy psikhologii, } \\
\text { no. } 5 \text {, p. } 3-16\end{array}$ & 1968 \\
\hline II & $\begin{array}{l}\text { Psikhicheskoe } \\
\text { otrazhenie }\end{array}$ & $\begin{array}{l}\text { Chuvstvennyi obraz i model' } \\
\text { v svete leninskoi teorii otrazheniia }\end{array}$ & $\begin{array}{l}\text { Voprosy psikhologii, } \\
\text { no. } 2 \text {, p. } 34-45\end{array}$ & 1970 \\
\hline III & $\begin{array}{l}\text { Problema deiatel'nosti } \\
\text { v psikhologii }\end{array}$ & $\begin{array}{l}\text { Problema deiatel'nosti } \\
\text { v psikhologii }\end{array}$ & $\begin{array}{l}\text { Voprosy filosofii, } \\
\text { no. } 9 \text {, p. } 95-108\end{array}$ & 1972 \\
\hline IV & $\begin{array}{l}\text { Deiatel'nost' } \\
\text { i soznanie }\end{array}$ & $\begin{array}{l}\text { Deiatel'nost' } \\
\text { i soznanie }\end{array}$ & $\begin{array}{l}\text { Voprosy filosofii, } \\
\text { no. } 12 \text {, p. } 129-140\end{array}$ & 1972 \\
\hline $\mathrm{V}$ & $\begin{array}{l}\text { Deiatel'nost' } \\
\text { i lichnost' }\end{array}$ & $\begin{array}{l}\text { Deiatel'nost' } \\
\text { i lichnost' }\end{array}$ & $\begin{array}{l}\text { Voprosy filosofii, } \\
\text { no. } 4 \text {, p. } 87-97 \text {; } \\
\text { no. } 5 \text {, p. } 65-78\end{array}$ & 1974 \\
\hline Apêndice & Prilozhenie & $\begin{array}{l}\text { Psikhologicheskie voprosy } \\
\text { soznatel'nosti ucheniia }\end{array}$ & $\begin{array}{c}\text { Problemy psikhologii } \\
\text { ponimaniia. Izvestiia APN } \\
\text { RSFSR, vyp. 7; p. 3-40 }\end{array}$ & 1947 \\
\hline
\end{tabular}

A outra importante coletânea da obra de Leontiev é The Problems of Psyche Development (1959), que, só na União Soviética (ou seja, não mencionando as traduções estrangeiras do livro), foi reproduzida no todo em 4 edições (edições 2 a 4 em 1965, 1972 e 1981, respectivamente), valendo ao autor o prestigioso Prêmio Lenin, em 1963. Embora o projeto desse livro lembre o da obra Atividade. Consciência. Personalidade, o livro é extraordinário. Seu capítulo de abertura, intitulado "O problema da emergência da sensação" [Problema vozniknoveniia oshchushcheniia], que compõe um quarto de todo o livro, foi a primeira publicação de um fragmento da tese de doutoramento de Leontiev, fragmento esse que não apenas esclarece as atividades de pesquisa dele e de sua equipe em Carcóvia e Moscou, entre 1933 e 1936, mas também nos oferece uma visão do desenvolvimento empolgante do programa de pesquisa de ciência de vanguarda, genuinamente vigotskiano, o qual tem sido, em grande parte, ignorado e menosprezado até a atualidade pela comunidade acadêmica internacional.

Tudo isso explica nosso interesse subjetivo no primeiro livro de Leontiev, O Desenvolvimento da Memória, de 1931, escrito exclusivamente no espírito da "psicologia instrumental" de Vigotski da década de 1920, bem como a importância objetiva de tal obra.

\section{Razvitie Pamiati: Estudo Pioneiro da "Psicologia Instrumental" Mecanicista de Vigotski}

Além de ser o primeiro importante livro de Leontiev, a pesquisa que subsidia O Desenvolvimento da memória, de 1931, é de bastante relevância, pois o livro verdadeiramente se destaca por ser a única grande 
obra realizada como monumento sólido - teórica e empiricamente fundamentado - e, em certo sentido, como manifesto do programa de pesquisa "instrumental" de Vigotski em seu período reducionista e mecanicista dos anos 1920. De fato, apesar de uma série de outros trabalhos publicados sob autoria de Vigotski, Luria ou ambos, nenhum pode ser considerado uma contribuição genuinamente inovadora ou original para a "nova psicologia” defendida por Vigotski. Isso porque eram materiais didáticos escritos para alunos de graduação com formação deficiente (p. ex., que não tiveram a devida escolarização no Ensino Médio), oriundos das massas democráticas dos tempos pós-revolucionários (como os textos Pedologia da Idade Escolar, de 1928, ou Pedologia do Adolescente, em três volumes, de 1929 a 1931) ou obras científicas populares para o público geral (como Estudos da História do Comportamento. Macaco, Homem Primitivo, Criança ou Imaginação e Criação na Infância, ambos de 1930). De fato, esses volumes, de 1930 a 1931 - em conjunto com o livro Dicionário Psicológico, publicado com atraso considerável em 1931, que Vigotski produziu em coautoria com seu colaborador mais jovem, Boris Varshava (1900-1927) - foram os últimos livros com o nome de Vigotski na capa que o autor chegou a ver impressos ${ }^{4}$. Além desses, havia um apanhado de projetos independentes de pesquisa de Luria realizados em paralelo com o seu envolvimento nas pesquisas de Vigotski e bastante distanciados de sua pauta científica. Um exemplo disso é o famoso e influente livro A Natureza dos Conflitos Humanos, publicado em inglês, nos Estados Unidos, em 1932.

Em contrapartida, o Razvitie Pamiati [O Desenvolvimento da Memória], de Leontiev (LEONTIEV, 1931), apresentava grande quantidade de dados e generalizações teóricas que foram realizadas dentro do programa de pesquisa de Vigotski e refletem plenamente o estado da arte da teoria emergente desse autor até o fim de 1929 (a composição do livro foi formalmente finalizada em 1930, aproximadamente, mas houve atraso na impressão e na publicação). O livro é uma expressão perfeita do trabalho de teorização e pesquisa de Vigotski nos anos 1920 pela beleza simplista e ingênua do "instrumentalismo" vigotskiano inicial.

A principal ideia era o desenvolvimento do domínio do próprio comportamento e do desempenho. Nesse estudo em particular, a questão era o domínio dos processos psicológicos da memória e da atenção para os sujeitos do estudo. No modo característico desse período de pensamento, os pesquisadores, como projetistas do estudo, nunca questionaram a vontade dos sujeitos de atingir um bom desempenho psicológico, pois isso - de modo lamentável - era assumido como autoevidente. A partir daí, do ponto de vista teórico, os pesquisadores postularam que existiam dois tipos de funções psicológicas: as "inferiores", "naturais", e as "superiores", "culturais". Tais teóricos nunca se deram o trabalho de definir claramente o que seriam as funções psicológicas "inferiores", tampouco de definir exatamente o que as distinguiria dos processos puramente fisiológicos. Em vez disso, entretanto, articularam o que viram como a principal diferença entre o indefinido "inferior" e o avançado "superior". A distinção foi a origem desse último: acreditava-se que as funções "superiores" emergiam como resultado do uso instrumental de algumas "ferramentas culturais", criadas artificialmente pela humanidade durante o processo de desenvolvimento cultural da espécie humana. Em seguida, partindo desse pressuposto relativamente geral sobre a história do desenvolvimento cultural do Homo sapiens, os pesquisadores deram um salto dramático para a ontogênese, ou seja, o desenvolvimento individual das crianças, que eram, de fato, o grupo mais importante de participantes do estudo.

Com o intuito de demonstrar que suas afirmações e seus pressupostos teóricos estavam corretos, os pesquisadores apresentaram aos sujeitos alguns itens que pensavam ser "ferramentas culturais" totalmente desprovidos de sentido. Postularam que os "signos" ajudariam os participantes do experimento a dominar os processos psicológicos de recordação e de atenção por meio da associação desses signos com os objetos a ser lembrados ou para os quais deveria atentar. Os procedimentos e os principais resultados desse estudo são bem-conhecidos e foram descritos e discutidos amplamente em outros trabalhos. A discussão sobre o método de "dupla estimulação" (YASNITSKY, 2018, p. 37-40), sobre a "psicologia instrumental” de Vigotski 
(YASNITSKY, 2018, p. 65-69) e sobre as "descobertas inesperadas" de sentido das palavras, do diálogo e da fala interior (YASNITSKY, 2018, p. 69-73) se encontram no livro mais recente de Yasnitsky, de 2018, Vygotsky: An Intellectual Biography (YASNITSKY, 2018), o qual, segundo resenha, trouxe ao autor a elogiosa reputação de ser um "novo líder mundial na realização de um criterioso trabalho analítico do legado de Vigotski"s. Basta dizer que, em seu primeiro livro, Leontiev fez um relato triunfante sobre a demonstração empírica realizada em contextos experimentais de tais processos. Portanto, o autor pôde defender a descoberta daquilo que os estudiosos acreditavam ser o desenvolvimento de "funções psicológicas culturais" da memória lógica e da atenção voluntária, com a ajuda da "mediação" de signos sem significado como "ferramentas culturais". Isso explica por que, nesse livro, as "funções superiores" foram também denominadas "funções mediadas".

\section{O Revisionismo de Leontiev como Projeto de Ciência de Vanguarda}

Contudo, quase de imediato, o triunfo se transformou em desastre. Devido a uma combinação de fatores pessoais e sociais, os pesquisadores do Círculo Vigotski-Luria logo (e mesmo anteriormente à publicação do livro) perceberam uma série de problemas fatais em seus pressupostos teóricos, no projeto do estudo, nos procedimentos analíticos e nos achados e interpretações-chave. A primeira tentativa de corrigir a situação de alguma maneira ocorreu na própria introdução do livro de Leontiev, introdução essa de autoria de Vigotski. Aparentemente, isso não foi suficiente. A ela se seguiu outro texto, publicado separadamente como pequena brochura assinada por Vigotski e Leontiev - sua única publicação em coautoria. Essa brochura saiu em 1932 e foi distribuída em conjunto com o livro, como apêndice, com alguns esclarecimentos a mais, uma autocrítica, e uma tentativa filosoficamente fundamentada de corrigir falhas teóricas do livro (VYGOTSKII; LEONTIEV, 1932). Cabe fazer um comentário: o leitor brasileiro tem a oportunidade de ler esse texto, publicado pela primeira vez em português, neste dossiê especial dos Cadernos CEDES.

Entretanto, essas numerosas falhas não poderiam ser corrigidas a não ser em outro estudo experimental, o que não teve início até Leontiev estabelecer um importante centro de pesquisa em Carcóvia ${ }^{6}$, capital da Ucrânia soviética na época, para onde (juntamente com Luria) se mudou em 1931. Ali, Leontiev rapidamente recrutou uma nova equipe de pesquisa, que cuidadosamente investigou os problemas do "instrumentalismo" vigotskiano, inaugurando pesquisas sob a supervisão de Leontiev. Tratava-se de três eixos primordiais: em primeiro lugar, um estudo revisionista sobre a memória, realizado prioritariamente pelo aluno de Lontiev, Piotr Zinchenko (1903-1969) ${ }^{7}$; em segundo lugar, um estudo pioneiro sobre a origem da sensação, o qual forneceu a Leontiev dados experimentais para sua própria tese de doutoramento; e, em terceiro, depois que Leontiev deixou Carcóvia, em 1934, uma pesquisa de grande escala sobre a percepção realizada por Aleksandr Zaporozhets, ex-aluno de Leontiev e seu sucessor administrativo em Carcóvia, além de futuro colaborador de Leontiev em seu segundo livro. Esse importante estudo da equipe de Zaporozhets pode ser considerado uma continuidade direta e aperfeiçoada do trabalho de Vigotski sobre a "psicologia da arte" e sua contribuição para o desenvolvimento do "novo homem", ou Super-homem, no linguajar de Vigotski. Para nosso pesar, o manuscrito final da tese de doutoramento de Zaporozhets foi destruído durante a Segunda Guerra Mundial na cidade de Carcóvia, severamente bombardeada e praticamente destruída, ocupada e retomada repetidamente pelas forças nazistas e do Exército Vermelho soviético. A discussão detalhada das pesquisas da equipe de Zaporozhets foge ao escopo deste artigo. Felizmente, esses estudos estão suficientemente bem-apresentados e discutidos numa série de publicações da assim chamada "Escola de Psicologia de Carcóvia” (YASNITSKY; FERRARI, 2008a, 2008b).

Tudo indica que Aleksei N. Leontiev tenha aprendido bem a lição com seu primeiro livro e suas múltiplas falhas. De fato, o estudo de Piotr Zinchenko, sob orientação de Leontiev, demonstrou perfeitamente 
a compreensão clara das principais fragilidades do "instrumentalismo" de Vigotski, que ele examinou mais criticamente nos seus escritos "revisionistas", tais como os já mencionados anteriormente (VYGOTSKII; LEONTIEV, 1932), bem como nas suas copiosas anotações particulares e apresentações públicas do período entre 1930 e 32. De modo semelhante ao "Vigotski revisionista" e alguns de seus contemporâneos - como o fundador da psicologia marxista soviética, Sergei Rubinstein (1889-1960) (YASNITSKY, 2020) -, Zinchenko criticou de forma generosa e muito corretamente a distinção radical entre as funções "naturais" inferiores e as "culturais" superiores. Além disso, deu a entender que tinha conhecimento sobre a autocrítica de Vigotski quanto a funções psicológicas isoladas em favor dos sistemas de tais funções: em sua pesquisa, Zinchenko investigou não uma "função de memória", isolada e relativamente abstrata, como uma "função" que de fato existiria. Ademais, astutamente evitou uma predisposição implícita a uma "memória" unificada, como, presumivelmente, uma capacidade cognitiva tripartite para "armazenamento, conservação e recuperação de informações", derivada do linguajar das ciências da computação e da cognição, que ganhariam proeminência na psicologia influenciada e dominada pelo estilo de pensamento norte-americano pós-Segunda Guerra Mundial. Em vez disso, Zinchenko focou no processo concreto da recordação no contexto do mundo real. Assim, o projeto de seu estudo remonta, vagamente, ao "método instrumental" de "dupla estimulação", mas, no lugar de signos sem sentido (como noções teóricas que ajudam a explicar o processo de "mediação" e "internalização"), Zinchenko reconceitualizou as "ferramentas psicológicas" como portadoras de significado objetivo e sentido subjetivo - a distinção e a interconexão desses dois conceitos (e os muitos derivados de "sentido" e "consciência") são absolutamente essenciais (YASNITSKY; VAN DER VEER, 2016a).

Zinchenko e seu supervisor acadêmico, Leontiev, demonstraram que recordar, como processo psicológico vivo e dinâmico no contexto do mundo real, é uma função da atividade concreta significativa ${ }^{8}$ e das operações com objetos. Diferentemente dos primeiros estudos de Vigotski e Leontiev sobre o desenvolvimento artificial da memória lógica voluntária, a evocação, nos experimentos de Zinchenko e Leontiev, era involuntária, mas, por fazer parte de uma atividade pessoalmente significativa, em muitas instâncias pela sua eficiência, poderia até ultrapassar a memorização voluntária, porém mecânica, dos estudos de Vigotski. Além disso, Zinchenko e Leontiev destacaram a diferença entre objeto e plano de fundo da atividade, de modo similar ao par conceitual figura e fundo da vertente Gestalt ${ }^{9}$. Demonstraram que não somente o objeto da atividade significativa é evocado involuntariamente em agência, mas também até mesmo os objetos do fundo são recordados, ainda que numa razão consideravelmente mais baixa. Poderia ser especulado que recordar os objetos de fundo é parcialmente atribuído ao sentido pessoal subconsciente subjetivo que esses objetos têm para as pessoas. Entretanto, essa é uma proposta teórica que não parece nunca realmente ter ocorrido aos criadores do estudo.

O instigante estudo de Zinchenko e Leontiev pertence aos clássicos da pesquisa psicológica e, em muitos sentidos, antecedeu o desenvolvimento posterior da psicologia ocidental (CRAIK; LOCKHART, 2008; MACE, 2008; MCCAFFERTY, 2008; MESCHERYAKOV, 2008). Entretanto, toda a beleza da proposta de Vigotski de uma ciência de vanguarda da psicologia do Super-homem se descortina nas pesquisas ousadas da equipe de Leontiev sobre a emergência e o desenvolvimento da sensação, pesquisas essas que, pelos padrões da ciência pós-positivista contemporânea, poderiam ser consideradas marginalmente "científicas", na fronteira com a parapsicologia.

De fato, na sua pesquisa de doutorado, Leontiev pressupôs que a sensação poderia ser desenvolvida em contextos experimentais - não somente aqueles que existem normalmente nos seres humanos, mas também aquilo que não se observa em circunstâncias normais. Nesse caso, Leontiev testou a habilidade humana de desenvolver a sensação de cor da luz pela pele da mão humana, o que, por todos os padrões do comportamento médio "normal" humano, seria entendido como habilidade extrassensorial 
Nos ambientes experimentais rigorosos dos laboratórios psicofisiológicos dos estudos de Leontiev em Moscou e Carcóvia - realizados sob a supervisão do aluno mais próximo de Ivan Pavlov e seu herdeiro intelectual, Leon Orbeli -, Leontiev foi capaz de demonstrar algo incrível: em determinadas circunstâncias os sujeitos de seus experimentos eram capazes de desenvolver habilidades extrassensoriais! O espírito vanguardista do programa vigotskiano de pesquisa super-otimista se revela na crença dos pesquisadores na plasticidade praticamente infinita da natureza humana, na ousadia extrema dos seus objetivos de pesquisa e no radicalismo do estudo, que teria sido quase inconcebível em qualquer outro meio intelectual que não o ambiente intelectual soviético.

Lamentavelmente, a grandeza e o potencial pleno desse estudo permaneceram inexplorados até os dias de hoje. O estudo foi concluído em 1940. O acadêmico Leon Orbeli, supervisor e oficialmente principal fisiologista soviético, aprovou a pesquisa. Essa também recebeu a aprovação de Sergei Rubinstein, examinador da banca, primeiro psicólogo a, logo a seguir, tornar-se membro correspondente da Academia de Ciências da URSS e, oficialmente, principal psicólogo soviético marxista. A União Soviética de Josef Stalin ainda era melhor amiga da Alemanha de Adolf Hitler. A invasão nazista da União Soviética ainda não tinha começado. Leontiev defendeu sua tese com sucesso nos primeiros anos da Segunda Guerra Mundial, no instituto de Orbeli, na "cidade de Lenin", Leningrado. Esse foi o verdadeiro triunfo da ciência de Super-homem vigotskiana e da pesquisa revolucionária de vanguarda do estilo singularmente soviético. No entanto, apesar de algumas singelas tentativas de dar continuidade pós-Segunda Guerra Mundial, por exemplo, ao trabalho pioneiro de Aleksandr Zaporozhets e seu colaborador, essa linha de experimentação radical e de vanguarda nunca foi inteiramente retomada. Contar a história desse projeto científico de vanguarda seria uma empreitada realmente instigante.

Contudo, essa seria uma história completamente à parte, que foge ao escopo deste artigo.

\section{Agradecimento}

As organizadoras do dossiê agradecem a Lucia Reily pela revisão técnica do texto em inglês e a tradução do mesmo para o português.

\section{Notas}

1. Sobre os clãs de psicólogos soviéticos e sua disputa pelo poder, o éthos idiossincrático dos psicólogos soviéticos e russos contemporâneos, o "modelo stalinista de ciência" e o "arquétipo da psicologia soviética", ver Yasnitsky (2016"), também disponível em espanhol como primeiro capítulo de Yasnitsky et al. (2016).

2. Este texto também está disponível em espanhol como capítulo do livro Yasnitsky et al. (2016).

3. Como exemplo interessante da "ciência de vanguarda", tem-se o caso do acadêmico russo, filólogo e linguista expatriado, Roman Jakobson (1896-1982), contemporâneo de Vigotski e colaborador de Luria (TOMAN, 1995).

4. Para a mais confiável bibliografia acadêmica de Vigotski, ver Van der Veer e Yasnitsky (2016a). Para uma visão panorâmica detalhada das publicações de Vigotski, ver também Van der Veer e Yasnitsky (2016b). Van der Veer e Yasnitsky (2016b) está disponível também em espanhol, como capítulo do livro Yasnitsky et al., (2016).

5. Retirado do endosso do livro, por Jaan Valsiner, Universidade de Aalborg, Dinamarca, na capa (grifos nossos): "Esta é a primeira reportagem minuciosa da vida e da obra deste acadêmico russo judeu desde meu trabalho com René van der Veer, há mais de 25 anos. (Understanding Vygotsky, 1991). As teorias psicológicas de Vigotski, baseadas nos seus profundos sentimentos pelo teatro e pela literatura, continuam a fascinar os acadêmicos mundialmente. Claramente, Yasnitsky emergiu como o novo líder mundial, ao realizar um criterioso trabalho analítico sobre a herança de Vigotski.” Nessa linha, o trabalho um pouco anterior do autor e seus colaboradores (YASNITSKY; VAN DER VEER, 2016b) recebeu grandes elogios do acadêmico cubano radicado no Brasil Fernando Luis González Rey: "Este livro ao mesmo tempo questiona mitos e introduz novos pontos 
de partida no estudo contemporâneo das obras clássicas de Vigotski.” Para uma discussão mais completa do tema por esse mesmo autor, em espanhol, ver (Rey, 2016).

6. Conhecida por Kharkov, nome da cidade na ortografia russa tradicional.

7. Piotr (Petr ou Peter; Petro em ucraniano) Zinchenko (não se deve confundir com Vladimir Petrovich Zinchenko [19312014], seu filho, também um renomado psicólogo soviético - e, posteriormente, russo) permaneceu praticamente desconhecido para o leitor brasileiro. Assim, a exposição mais longa e talvez melhor do trabalho de Zinchenko em português se encontra na tese de doutorado de Sandro Henrique Vieira de Almeida, intitulada Psicologia HistóricoCultural da Memória, defendida na Pontifícia Universidade Católica de São Paulo (PUC-SP), em 2008. No momento da escrita do presente artigo, a tese completa encontra-se disponível on-line em: <http://livros01.livrosgratis.com.br/ cp056390.pdf $>$. Para uma discussão do estudo de Zinchenko em questão, ver especificamente as páginas 86 a 102 . Por motivos evidentes, o autor do presente texto não tem de concordar com cada afirmação colocada na dissertação em questão, porém recomenda fortemente o texto para leitores lusófonos. Além disso, alguns dos estudos e publicações de Zinchenko dos anos 1930 se encontram disponíveis em traduções em inglês (ZINCHENKO, 1983, 2008). Pode também ser proveitoso para o leitor conhecer a discussão sobre as pesquisas de Zinchenko e aquelas inspiradas por ele no seu desenvolvimento histórico em Mescheryakov (2008), Yasnitsky (2008) e Yasnitsky e Ivanova (2011).

8. A expressão "atividade significativa/tornada consciente" [osmyslennaia deiatel'nost'] foi suplantado por "atividade relacionada ao objeto" [predmetnaia deiatel'nost'] nas obras posteriores especulativas quase-marxistas de Leontiev.

9. Para as muitas interconexões entre os psicólogos soviéticos do Círculo Vigotski-Luria e os psicólogos teuto-americanos da psicologia da Gestalt, ver Yasnitsky e Van der Veer (2016b).

\section{REFERÊNCIAS}

CRAIK, F.; LOCKHART, R. Levels of processing and Zinchenko's approach to memory research. Journal of Russian and East European Psychology, v. 46, n. 6, p. 52-60, 2008. https://doi.org/10.2753/ RPO1061-0405460605

GONZÁLEZ-REY, F. L. Prólogo. In: YASNITSKY, A. et al. (eds.). Vygotski revisitado: Una historia crítica de su contexto y legado. Buenos Aires: Miño y Dávila Editores, 2016, p. 17-35.

HAGGBLOOM, S. J. et al. The 100 most eminent psychologists of the 20th century. Review of General Psychology, v. 6, n. 2, p. 139-152, 2002. https://doi.org/10.1037//1089-2680.6.2.139

KEILER, P. A history of the social construction of the "cultural-historical". In: YASNITSKY, A. (ed.). Questioning Vygotsky's legacy: Scientific psychology or heroic cult. London/New York: Routledge, 2019, p. 91-130.

KREMENTSOV, N. Revolutionary experiments: The quest for immortality in Bolshevik science and fiction. Oxford: Oxford University Press, 2013.

LAMDAN, E. Vygotsky's "significant other": Alexander Luria's contribution to the development of Vygotsky's ideas. In: YASNITSKY, A. (ed.). Questioning Vygotsky's legacy: Scientific psychology or heroic cult. London/New York: Routledge, 2019, p. 65-90.

LEONTIEV, A. N. Razvitie pamiati. Eksperimental'noe issledovanie vysshikh psikhologicheskikh funktsii [Development of memory. Experimental research on higher psychological functions]. Moscow: Uchpedgiz, 1931. 
LEONTIEV, A. N. Lev Semenovich Vygotskii. Sovetskaia psikhonevrologiia, n. 6, p. 188-190, 1934.

MACE, J. H. The involuntary/voluntary distinction: Implications for learning and memory and the contributions of P. I. Zinchenko. Journal of Russian and East European Psychology, v. 46, n. 6, p. 46-51, 2008. https://doi.org/10.2753/RPO1061-0405460604

MCCAFFERTY, S. G. Zinchenko's research on memory and pedagogical applications: Commentary on Meshcheryakov. Journal of Russian and East European Psychology, v. 46, n. 6, p. 41-45, 2008. https://doi.org/10.2753/RPO1061-0405460603

MESCHERYAKOV, B. G. The mnemic effects of P.I. Zinchenko. Journal of Russian and East European Psychology, v. 46, n. 6, p. 15-40, 2008. https://doi.org/10.2753/RPO1061-0405460602

TOMAN, J. The magic of a common language: Jakobson, Mathesius, Trubetzkoy, and the Prague Linguistic Circle. Cambridge: MIT Press, 1995.

VAN DER VEER, R.; YASNITSKY, A. Vygotsky's published works: A(n almost) definitive bibliography. In: YASNITSKY, A.; VAN DER VEER, R. (eds.). Revisionist Revolution in Vygotsky Studies. London/ New York: Routledge, 2016a, p. 243-260.

VAN DER VEER, R.; YASNITSKY, A. Vygotsky the published: Who wrote Vygotsky and what Vygotsky actually wrote. In: YASNITSKY, A.; VAN DER VEER, R. (eds.). Revisionist Revolution in Vygotsky Studies. London/New York: Routledge, 2016b, p. 73-93.

VYGOTSKII, L. S.; LEONTIEV, A. N. Predislovie k knige A. N Leont'eva “Razvitie pamiati”. In: Prilozhenie k knige A. N Leont'eva "Razvitie pamiati”. Moscow, [s. n.], p. 2-11, 1932.

YASNITSKY, A. Piotr Zinchenko's psychology: A brief history of ideas. Journal of the Russian and East European Psychology, v. 46, n. 5, p. 3-7, 2008. https://doi.org/10.2753/RPO1061-0405460500

YASNITSKY, A. The archetype of Soviet psychology: From Stalinism of the 1930s to the "Stalinist science" of our days. In: YASNITSKY, A.; VAN DER VEER, R. (eds.). Revisionist Revolution in Vygotsky Studies. London/New York: Routledge, 2016a, p. 3-26.

YASNITSKY, A. Unity in diversity: Vygotsky-Luria Circle as an informal personal network of scholars. In: YASNITSKY, A.; VAN DER VEER, R. (eds.) Revisionist Revolution in Vygotsky Studies. London/ New York: Routledge, 2016b, p. 27-49.

YASNITSKY, A. Vygotsky: An intellectual biography. London/New York: Routledge, 2018.

YASNITSKY, A. Vygotsky's science of superman: From utopia to concrete psychology. In: YASNITSKY, A. (ed.). Questioning Vygotsky's legacy: Scientific psychology or heroic cult. London/New York: Routledge, 2019, p. 1-21.

YASNITSKY, A. Sergei Rubinstein the founder of Soviet Marxist psychology: "Problems of psychology in the works of Karl Marx" (1934) and beyond. In: YASNITSKY, A. (ed.). A history of Marxist psychology: The golden age of Soviet science. London/New York: Routledge, 2020.

YASNITSKY, A. et al. (ed.). Vygotski revisitado: Una historia crítica de su contexto y legado. Buenos Aires: Miño y Dávila Editores, 2016. 
YASNITSKY, A.; VAN DER VEER, R. "Lost in translation": talking about sense, meaning, and consciousness. In: YASNITSKY, A.; VAN DER VEER, R. (Ed.) Revisionist Revolution in Vygotsky Studies. London \& New York: Routledge, 2016a. p. 229-239.

YASNITSKY, A.; VAN DER VEER, R. (Ed.) Revisionist Revolution in Vygotsky Studies. London \& New York: Routledge, 2016b.

YASNITSKY, A.; FERRARI, M. From Vygotsky to Vygotskian psychology: Introduction to the history of the Kharkov school. Journal of the History of the Behavioral Sciences, v. 44, n. 2, p. 119-145, 2008a. https://doi.org/10.1002/jhbs.20303

YASNITSKY, A.; FERRARI, M. Rethinking the early history of post-Vygotskian psychology: the case of the Kharkov school. History of Psychology, v. 11, n. 2, p. 101-121, 2008b.

YASNITSKY, A.; IVANOVA, E. F. Rethinking the early history of post-Vygotskian psychology: The case of the Kharkov school. History of Psychology, v. 11, n. 2, p. 101-121, 2008b. https://doi. org/10.1037/1093-4510.11.2.101

YASNITSKY, A.; IVANOVA, E. F. Remembering for the future: Grigorii Sereda in the history of Kharkov school of psychology. Journal of Russian and East European Psychology, v. 49, n. 1, 2011. https://doi.org/10.2753/RPO1061-0405490100

ZINCHENKO, P. I. The problem of involuntary memory. Soviet psychology, v. 22, n. 2, p. 55-111, 1983. https://doi.org/10.2753/RPO1061-0405220255

ZINCHENKO, P. I. On forgetting and remembering school knowledge. Journal of Russian and East European Psychology, v. 46, n. 5, p. 8-42, 2008.

Recebido: 01 Jul 2019

Aceito: 30 Nov 2019

Comitê Editorial do Cedes/Coordenação deste número:

Silvia Cordeiro Nassif e Maria Silvia Pinto de Moura Librandi da Rocha 